\title{
Speech strategy of anonymity in communication
}

\author{
Marina Bulavina ${ }^{1}$, Yulia Biryukova $^{1, *}$, Victoria Kurilenko ${ }^{1}$, Larisa Dunaeva ${ }^{2}$, Kristina Akhnina $^{1}$ \\ ${ }^{1}$ Peoples' Friendship University (RUDN University), 117198, Moscow, Russia \\ ${ }^{2}$ Lomonosov Moscow State University, 119991, Moscow, Russia
}

\begin{abstract}
The article examines Internet channels as new communicative functional systems in Telegram Messenger as it often happens that there are some anonymous channels that refuse to disclose their authorship. The analysis of anonymity in Telegram shows that there is a special communicative strategy that can be a verbal provocation aimed at activating the communicative interest of readers on the one hand and, on the other hand, it is a way of avoiding responsibility for the reliability of the reported news. It is possible to confirm that the new trend appears that includes the mixture of mass media and interpersonal communications
\end{abstract}

\section{Introduction}

Nowadays new forms of mass and interpersonal communication appear to interact between senders and recipients of information. It happens due to the development of digital communications.

In 2015 new channels appeared at Pavel Durov's Telegram messaging service. They made it possible to send messages to an unlimited number of subscribers. Currently Telegram is one of the fastest messenger in terms of downloads and audience size in Russia.

The scientists that deal with media note that this form of the communication is conceptually new. A channel in Telegram is something between a news line and a blog on a certain topic, while remaining the territory of freedom and media experiments. "The crossings or hybridizations of the media release great new force and energy as by fission or fusion. There must be no blindness in these matters once we have been notified that there is anything to observe... The hybridizing or compounding of these agents offers the especially favorable opportunity to notice their structural components and properties" [1].

In this article, the idea of the convergence of mass and interpersonal communication is considered in the particular aspect of anonymity as a communicative strategy implemented in the Telegram web-channels. In the Russian segment of Telegram communication, the authors of popular channels are, usually, famous journalists, bloggers, activists, politicians, or experts from many knowledge areas. However, the administrators of some existing anonymous channels refuse to disclose their authorship.

In comparison with other social networks, for example, Facebook, Twitter, Instagram, LiveJournal, in the Telegram channels, the recipient of a message has no opportunity to enter into a direct dialogue with its sender and other recipients. In fact, this is formally the addresser's monologic statement with an internal attitude toward dialogue, interaction with the audience. The impossibility of direct interaction between the sender and the recipient of a message requires that the author, while waiting for the reader's counter (often implicit) reaction, should exert additional rhetorical efforts in organizing internal dialogical communication. This attitude to communicative interaction with the addressee in the situation of bilateral anonymity forces the addresser to use various dialogic communication strategies and tactics.

\section{Literature review: the problem of anonymity in mass media and interpersonal communication}

For over a hundred years, the scientists have been studying the problem of anonymity. They have been searching for the definitions of this concept, comparing it with the concepts of confidentiality, uncertainty, unidentifiedness, hiding, etc. [2] ,[3],[4],[5],[6],[7].

While the researchers were searching it in the field of linguistics anonymity received the status of an interdisciplinary category: problems of hiding sender information are studied in banking services, medicine, sociology, mass media, and interpersonal communication cybersecurity, management, commerce.

The World Wide Web development let the problem of anonymity get the new dimensions. Anonymity has been recognized as a fundamental category of Internet communication: communicators can register under other people's names in e-mail, social networks, forums, media commenting systems, reporting unreliable data and hiding personal information.

It should be borne in mind that anonymity in communication arose long before the appearance of means of virtual communication. Communication

\footnotetext{
* Corresponding author: yu.birukova@gmail.com
} 
strategies for both complaints against a superior or a competitor in the practice of business communication and complaints against a neighbor in the practice of interpersonal social interaction are often implemented through the tactic of anonymous communication. In the Russian linguistic consciousness, this tactic is enshrined in a family of cognate words. However, mentally and stylistically, the lexemes included in this family have different colors (shades). For example, the adjective анонимный (anonymous) and the adverb анонимно (anonymously) imply "without specifying the name of the one who writes or reports something not signed" are estimatedly and stylistically neutral. The word 'анонимка' has a colloquial deprecative connotation implying "an anonymous letter informing someone of something offensive, unpleasant, compromising" (Ozhegov's Dictionary), while the stylistically neutral 'аноним' denoting 'an opus without the specified author's name" is obsolete and currently almost never used in any field of communication. In this case, the person writing such letters is indicated by the two lexemes: 'аноним' and 'анонимщик', which have different stylistic characteristics. The word аноним is used in book speech and does not have any evaluativity: "the author concealing his/her name". The word 'анонимщик', on the contrary, is stylistically and emotionally tinged (col., cont.) and means "a person writing anonymous letters". The word 'анонимщик' is masculine, with its feminine counterpart being 'анонимщица', while the word 'аноним' has no gender correlation in Russian, which indicates a greater prevalence of this phenomenon in everyday language.

Thus, the very phenomenon of concealing the authorship in the Russian linguistic consciousness has different evaluations and the corresponding words have different spheres of application.

Though some groups of people (IT specialists) say that anonymity in Internet communication does not exist because Internet communicants always 'leave traces' in one form or another, by which they can be identified", anonymity remains an urgent research problem in the field of communication also due to its multifacetedness and multidimensionality.

The problem of anonymity concerns all aspects of communication, i.e., actors, recipients, sources of information, information itself [4], and is relevant for both mass and interpersonal communications. Traditionally, anonymity in interpersonal communication is associated with problems of fear, insecurity, or possible conflictogenic situations. However, studies of anthropologists, sociologists, and linguists show that the interaction of communicants in conditions of anonymity is a more complex process than it may seem at first glance.

Anonymous communication is directly related to the opportunity/temptation to transmit untrue, false information; therefore, the recipient has to develop strategies and tactics for recognizing this kind of information and responding to it $[8,4]$. Various studies presented in the scientific literature propose models for detecting inaccurate, inauthentic, false information, or interactive deception $[9,10]$ investigate the context of communication, the degree to which the source is considered anonymous, the receiver's desire to identify the source (or further anonymize it), analyze the perception of an anonymous source and information itself, and identify cases of positive and negative effect of anonymous communication on message recipients [11]. The result of these and similar studies was the discovery of a correlation between anonymous senders of information, more prone to unreliability or deception, and recipients of such information, who are ready to truthfully and accurately discuss the information received anonymously rather than in personal communication.

Studies show that anonymity does not always imply hiding true information, deception or fraud. Experimental data [12] show that anonymity promotes deviations from the given rules provided that material compensation is received, while psychological preferences do not necessarily lead to violations of the social behavior norms even in the conditions of anonymity. Thus, while discussing complex, controversial, conflictogenic official issues, members of collectives mainly do not use the opportunity to hide their answers under the anonymous mask; the most negative opinions as well as constructive ideas are expressed personally but not anonymously [8].

The presented data suggest that anonymity as the most important category of Internet communication can serve as a means of managing interpersonal and mass communications. The theory of the "central anonymity paradigm" is essential to our study [3], which links anonymity (the author of a blog, source of information and/or information itself) with speech control procedures, when true information is hidden with the effect of decomposability. The implementation of speech control in communication encourages communicants to choose communication strategies and tactics [13].

The scientific hypothesis of our research was that the message sender's anonymity in Telegram communication is caused by the need to solve the problems of effective influence on the reader, which helps attract and fix attention to the channel author's communicative activity and extend the range of subscribers and casual readers (extended reach and coverage).

\section{Materials and methods}

The research was conducted within the framework of a pragmatic approach to the analysis of speech behavior in Internet communication. Processes of interaction between communicants are considered as purposeful speech behavior in accordance with the acts of planning the communication result desired by both communicating parties. This explains the reason for choosing the tactical-strategic aspect in a pragmatic approach to the study of speech material. Since web communication in Telegram does not stipulate for the reader's explicit response to written text in a blog (web channel), the researcher's task at the first stage is to identify strategies and tactics of the addresser's speech 
behavior in accordance with the planned result. By applying general scientific methods of deductive and inductive analysis, descriptive and comparative methods, component, stylistic and rhetorical, contextual analysis, discourse analysis, and the method of intent analysis, we can establish the speaker's obvious and hidden intentions and evaluate the effectiveness of verbal communication.

Content analysis was used for studying the content side of information transmitted to communication. Using this analysis, it became possible to identify the most characteristic language units that facilitate implementation of various tactics of the anonymity strategy in Telegram communication. Statistical methods made it possible to evaluate the perlocutionary effect produced by texts in Telegram channels. In discussing the obtained results, the method of external linguistic interpretation was used.

\section{Results and discussion}

The study showed that the speech anonymity strategy is implemented by such speech tactics connected with transmitting unreliable information as "Rumors", "Hints", "Game of authenticity", "Fold", "Exposing competitors", "Hypotheses/announcements of scenarios", and "Generalizing viewpoints".

The implementation of "Rumors" tactic is associated with deliberate ambiguity (the source of information, information itself), veiling the encoded meaning. As the studies [14] show, rumors carry out important, albeit temporary, unreliable, and social functions of interaction between communicants. Around rumors circulating in the community, a discussion of the group system of values and norms is built in the process of achieving a common moral position.

The use of speech methods for spreading rumors in Internet communication of a socio-political nature presupposes the speaker's orientation to a wide audience coverage, including this and insufficiently prepared news content consumers (audience ${ }^{1}$ ) ready to accept rumors for verified and reliable information; this and competent audience $^{2}$ searching for additional sources of information, capable of taking a critical approach to this type of information, but also needing it for analytical explanatory procedures. The mental-psychological basis for the interest of news recipients in the rumor model (audience $^{1}$ ) is the need to be involved in a higher category in the hierarchy of public relations and status; for an audience ${ }^{2}$, it becomes essential to "get down to bed-rock", to solve an analytical problem, to restore the cause-effect relations underlying the news event.

Using "Rumors" tactics, the addresser is externally removed from the transmitted information content, which, on the one hand, creates the information objectivity effect; on the other hand, helps avoid responsibility for the transmitted information reliability.

The speech anonymity strategy implemented through tactics of obvious rumors, hints, misinformation in Telegram can be called, in part, according to Zeno Vendler, 'illocutionary suicide' [15]. Verbs and verb phrases rumor has it, evil tongues say, it was rumored, adverbs and introductory words like allegedly supposedly, as if, by hearsay, jargonisms throw in, flash, spill the beans directly indicate the unreliability of transmitted information and work as a disruptive factor of news communication: S.I. Ozhegov's Explanatory Dictionary of the Russian Language comments on these lexemes as follows: rumor has it - (col.) From time to time to resume talking about something, discussing or transmitting rumors; evil tongues - gossips, slanderers; gossip is a rumor about smb./smth., based on inaccurate or obviously incorrect information (Ozhegov S.I., Shvedova 1999). Some Telegram channels introduce similar words into the account names, for example: Sport and gossips. However, in the comments, administrators hint at the content of the channel and the way it is transmitted through an oxymoron-based language game (honest gossips): Gossips about sport. But honest gossips, without manipulation and showdown.

It may seem that it is impossible to trust information submitted in this way.

However, it is precisely the persistent and self-exposing repetition of these linguistic units that transforms the addresser's speech action into a special communicative tactic aimed at enhancing the illocutionary effect of a statement as a whole. It is known that the repeatability (reproducibility) of communicative techniques and speech means is an important way of suggestion.

The accentuation of hiding the true source of information increases the interest in both information itself and the text author as an insider. A frank statement about possible unreliability of information does not deter but draws the reader.

"Rumors" tactic is the most frequent and productive in the anonymous Telegram communication implemented by such rhetorical steps as: a) "Third hand". In a message, a double (triple) reference is made to the source of information (the author - reference to the source - reference to the source of the source) according to the model: we (1) learned that in ... they said (2), the subject allegedly states that (3); b) "Information noise" (a lot of subjects of speaking): as they say; according to well-informed sources; according to our source; the opinion was expressed by X, supported by part of the company; c) "Sequence of rumors": the tactics of rumors are interwoven with tactics of direct indication of a reliable source of information, which increases confidence in the author of the post, but also unties (?) hands: in the case of unconfirmed/false information one can always refer to this depersonified they say): the government commission decided to make a report (the composition of the commission is known) + discuss next year with the future president (who is it?) + met with the British aristocracy (with whom exactly?) + they say, representatives of the $N$ family discussed the issue (which representatives exactly?). The hashtags are also used: \# Letters to the Editor; \# Details became known. 4) Plurality of versions: Rumors and versions of $N$.'s dismissal are on the increase. For the time being, the information on ... Supposedly ... 5) Reference to a generally accepted standard: as is now customary to say. 
The "Hints" tactic, affecting the addressee mentally and emotionally, is based on the linguistic mechanism of deliberate ambiguity, double-meaning, obscureness of the utterance. Transferring information through the "hints" tactics allows the addresser, if necessary, to evade responsibility for what has been said by appealing to the meaning of the message misunderstood by the addressee (I meant something completely different).

In Telegram posts, the author can provide information with a direct reference to the source, which uses hinting tactics ( $N$ hinted that ...) with the hinting attribution traditional for the Russian language worldview: hinted transparently, subtly, vaguely.

However, indirect hinting tactics is more often used. In information-analytical anonymous blogs, addressers actively use speech steps such as a) hinting through a logical premise with the need for the reader to restore the missing logical link (the following is taking place in $N$... The subject does not understand what is happening. But we know the reasons, don't we?); b) hinting through the paradoxicality of the conclusion. In a logical chain, the reader must independently conclude about a "coupling" of two unobviously related premises. The author of the channel can directly formulate a non-obvious conclusion. In particular, it is common to use the rhetorical step of commenting on a photograph of the subject of current socio-political and business events placed on social networks: "Nikolay $U$, giving a piggyback ride to the child of Sergey $M$ and Juliana $S$, subtly hints who can buy Forbes from $F$ “.; c) hinting at the absurdity by comparing two premises, one of which speaks of the positive dynamics in the development of events, but the conclusion is made of its negative effect. Indicative in this case is the speech technique used as an element of the author's style on the "Davydov Index" channel: Postmodern news; Cyberpunk news. The channel heading (Postmodern News) directly indicates the essence of the technique: to combine the uncombinable, carrying this process to an absurdity. The speech ends with the refrain: Well, what's wrong? d) hinting through the contradiction. Two contradictory facts are compared most often without comment. The conclusion is made by the reader. A possible variant of the author's inclusion in the context may be the preamble: Amazing coincidence.

Let us note that, when implementing the hint tactic, some authors of Telegram channels actively use polycode texts. Mixing advertising techniques, creating Internet memes, comics, humorous demotivators, involving creolized texts in oral and written speech testifies to the development of interpersonal and mass communication hybridization processes. Inserting audiovisual series in the texts, including modified works of art, leads to the compulsory involvement of the recipient in the process of perceiving aestheticized social phenomena. The role of art is being rethought, as Walter Benjamin spoke about [1], noting the change in the function of art when it became possible to reproduce it. At the same time, the actual aesthetic function becomes, in Benjamin's terminology, a related one: "Instead of being based on ritual, it begins to be based on another practice - politics".

Let us consider an example of this. In the "Davydov. Index" channel, against the background of the reproduction of the famous painting 'Barge Haulers on the Volga' by I. Repin (a precedent work with a high level of recognition by any category of Russian communicants), the following text is placed: "Do not rock the boat, otherwise we will spill the champagne". The multi-layered character of this hybrid text and the obvious precedent make it possible to read a transparent allusion to the acutely social content. The perception of such texts depends on the background knowledge of the communicants and the peculiarities of the speech situation.

"Playing authenticity" tactic is based on the rethinking (deformation) of the principles and methods of work of accredited media: the principles of truthfulness, objectivity, reasoning, and is realized through: 1) a summary of the past day information in mixing the global with the local, the current with the eternal, with orientation to imitation of the spoken language, spontaneity, causeless change of the topic. A high degree of recurrence in the use of this method makes it possible to achieve a suggestive effect; 2) techniques of a fictitious refusal to guess ("We will not speculate on why or for what reason") with a further assumption of a possible scenario (I will refrain from commenting on the essence of the negotiations, but only note that...); 3) a combination of confidence in the reliability of information with doubting tactic (it is a safe bet that, of course, it is obvious - hardly that, it is hard to suppose, it is much more likely, perhaps, it is not apparent that, it is possible).

"Fold" tactic is actively used as a rhetorical method for approaching the readers, assigning to them the information presented as assimilated independently: I-we-you-subjectiveness: Well, we are already glad that

"Exposing competitors" tactic suggests expressing one's own viewpoint through leveling the opposite viewpoint (i.e., stating its obvious wrongness). Negative-evaluative words and phrases, including jargonisms and slang expressions (leaks, an open secret, a crazy idea), derogatory evaluations of the opponent's cognitive processes (it is known in advance, and so it is clear; everyone understands it; it is strange to expect) are rhetorical means of implementing this tactic. Nevertheless, a leak in "Vedomosti" is an open secret. Everyone understands that ...; The best arguments against the Pension Reform are how it is covered by $N$ and other media. It is strange to expect that an audience of 40-55 years old, who are dissatisfied with the Reform more than others and who are the first to be calmed, will not see this crazy working out of the idea.

"Hypotheses-announcements" tactic is more often implemented as questions (I wonder if $N$ will touch upon regional problems.) or assumptions (And will this campaign be funded by N? We will find it out later; This option has already been on the sidelines for several months. The more interesting the outcome of the story will be; One cannot exclude this possibility - they say that ...), thus increasing interest in the stated topic. 
"Generalizing viewpoints tactic". Attributing one's own viewpoint to "everyone" is a well-known rhetorical manipulative move, actively used precisely in a situation of dubious information reliability and the source's anonymity: Well now, who benefits from raising the retirement age? We all!; Everyone sees, reads, angrily comments on and sends to one another the speech of the Deputy O. via Viber and WhatsApp.

The question of the perlocutionary effect of communicative efforts undertaken by anonymous authors to attract the recipients's attention should be the subject of a special study. However, even at the first consideration of this issue it is possible to "read" the effect produced by anonymous communication on the addressee. Among the indicators of this effect are the following:

1. A number of anonymous Telegram channels of the Russian segment, such as Stalingulag (288130), Nezygar' (159308), Metodichka (51579), are among the most popular (the number of subscribers is given in brackets) sources of socio-political information and analytics in the Russian segment. Cf. Telegram media channels and Telegram personal channels of famous Russian journalists: Meduza (151334), TV Dozhd' (42245), Snob (27840), Rossiyskaya Gazeta (33741), Davydov. Index (151460), A. Plyushchev (33123), O. Kashin (22975).

Table 1. The number of subscribers and views of popular Telegram channels (the Russian segment).

\begin{tabular}{|c|c|c|c|c|}
\hline $\begin{array}{l}\text { Channel } \\
\text { authorizatio } \\
\mathrm{n}\end{array}$ & $\begin{array}{l}\text { Channel } \\
\text { name }\end{array}$ & $\begin{array}{l}\text { Number } \\
\text { of } \\
\text { subscrib } \\
\text { ers }\end{array}$ & $\begin{array}{l}\text { Daily } \\
\text { increas } \\
\text { e }\end{array}$ & $\begin{array}{l}\text { Averag } \\
\text { e views }\end{array}$ \\
\hline \multirow[b]{5}{*}{ 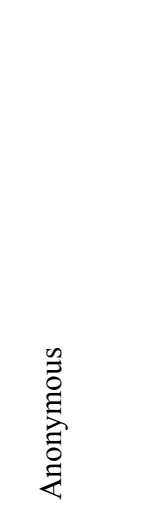 } & Nezygar & 159308 & 324.17 & 38050 \\
\hline & Karaulny & 74548 & & 10700 \\
\hline & Metodichka & 51579 & 54.74 & 20980 \\
\hline & Stalingulag & 288130 & 558.36 & 273200 \\
\hline & $\begin{array}{l}\text { Dvoynaya } \\
\text { sploshnaya } \\
\text { Murzilka }\end{array}$ & $\begin{array}{l}3389 \\
137747\end{array}$ & $\begin{array}{l}15.2 \\
32\end{array}$ & $\begin{array}{l}20340 \\
21200\end{array}$ \\
\hline \multirow{5}{*}{ 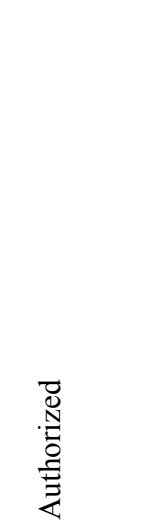 } & $\begin{array}{l}\text { Davydov. } \\
\text { Index }\end{array}$ & 151460 & 392.49 & 46960 \\
\hline & Oleg Kashin & 22975 & 17.41 & 12020 \\
\hline & $\begin{array}{l}\text { Ekaterina } \\
\text { Vinokurova }\end{array}$ & 7384 & 6.52 & 2520 \\
\hline & $\begin{array}{l}\text { Alexandr } \\
\text { Plyushchev }\end{array}$ & 33123 & 61.51 & 10750 \\
\hline & RBK & 7183 & 21.3 & 1400 \\
\hline
\end{tabular}

\begin{tabular}{|l|l|l|l|l|}
\hline & Meduza & 151334 & 395.2 & 19180 \\
\cline { 2 - 5 } & The Bell & 20882 & 51.58 & 8020 \\
\cline { 2 - 5 } & $\begin{array}{l}\text { Dozhd (TV } \\
\text { Rain) }\end{array}$ & 42245 & 78.63 & 6200 \\
\hline
\end{tabular}

The data in the table show that by the number of subscribers and its daily increase, anonymous channels are more in demand by readers as compared to the authorized ones in the ratio of $2: 1$.

2. Telegram channels are equipped with view counters to record the level of readers' interest in certain information and how it is presented. In terms of "average number of views of one post" the anonymous channels outperform the identified channels in the ratio of about $5: 1$.

3. The posts of the channels use the "fellow competitors" citation, which indicates the relevance of presented information, its commenting and analyzing. Complimentary references to well-known competitive channels make it possible to use the "bull operation" tactic in developing one's own channel, attracting attention to it: "There are nuances that the omniscient Nevygar does not seem to know about". This "roll call" creates a kind of polylogue between the participants of Telegram communication. Peculiar features of such polylogue can be a prospect for research.

4. According to media reports, representatives of official media, social and political activists as well as representatives of big business and government structures are actively involved in analyzing information offered by anonymous channels.

\section{Conclusion}

In the article it is confirmed the emerging trend towards convergence of the nature of communication in mass media and in interpersonal communications. The tactics of rumors, hints, uncertainty of the subject of the action, traditionally realized in interpersonal communication, combined with tactics of communicating actual information and adjusting to its authenticity characteristic of the mass media, attest to this.

The idea of anonymity as a speech strategy allows us to bring together both communicative fields. The anonymous mask awakens in the reader/addressee the desire to unravel the riddle of authorship, to clarify the personal characteristics of the author, to build his/her social portrait. The removal of the anonymous mask, first of all, is associated with the problem of trust/distrust in the information presented in a blog.

The prospect of research can be considered the development of models for building a polylogue between the authors of anonymous blogs and their readers. This will make it possible to clarify the goals, objectives, means and consequences of verbal behavior of anonymous authors in web communications. It is also important to develop a methodology for determining the degree of reliability of the information presented. 
The conducted analysis does not give grounds to assert that any anonymous Telegram channel uses anonymity as a speech strategy to intensify the illocutionary and perlocutionary effects of a statement. This can be exemplified by the Telegram channels Stalingulag and Politjoystick: an analysis of their speech material showed that the authors practically do not use speech tactics in the framework of the anonymity strategy, but enforce the illocutionary effect of statements in other ways.

\section{References}

1. McLuhan, H Marshall, Hybrid Energy: Les Liaisons Dangereuses, Understanding Media: The Extensions of Man. 5.. (NY: McGraw Hill, 1964)

2. W. Benjamine The Work of Art in the Age of Mechanical Reproduction, Illuminations 211-244. Retrieved from: http://web.mit.edu/allanmc/www/benjamin.pdf (London: Fontana, 2011)

3. J. Ponese. The Southern Journal of Philosophy, Navigating the Unknown: Towards a Positive Conception of Anonymity, 51,3, 320-344. Retrieved from:https://onlinelibrary.wiley.com/doi/full/10.1111 /sjp.12035 (2013)

4. J. Ponese,. Journal of Social Philosophy, The Ties That Blind: Conceptualizing Anonymity 45, 3, 304322. Retrieved from: https://onlinelibrary.wiley.com/doi/full/10.1111/josp. $\underline{12066}(2014)$

5. E. Malushko, O. Maletina, V. Tsybaneva, Advances in Social Science Education and Humanities Research (ASSEHR), Teaching Discussion Skills As Part Of Further Teachers' Training, 97, 175-180 (2017)

6. C.R. Scott., Communication Theory, To Reveal or Not to Reveal: A Theoretical Model of Anonymous Communication., 8,4, 381-407, (1998).
7. M.R. Zheltukhina, L.G. Vikulova, S.V. Mikhailova, L.A. Borbotko, A.R. Masalamova. XLinguae,. Communicative theatre space in the linguistic and pragmatic paradigm. 10, 2, 85-100 (2017)

8. S. Burnett, L. Illingworth. Knowledge and Process Management, Anonymous knowledge sharing in a virtual environment: a preliminary investigation, $\mathbf{1 5}$, 1, 1-11 (2008)

9. J.K. Burgoon, Human Communication Research, Rejoinder to Levine, Clare et al. Comparison of the Park-Levine Probability Model Versus Interpersonal Deception Theory: Application to Deception Detection, 41, 3, 327-349. (2015)

10. L.M. Van Swol, M.T. Braun, Journal of Communication, Channel Choice, Justification of Deception, and Detection, 64, 6, 1139-1159. Retrieved from: :https://onlinelibrary.wiley.com/journal/14602466(20 14)

11. S.A. Rains, C.R. Scott, Communication Theory, To Identify or Not to Identify: A Theoretical Model of Receiver Responses to Anonymous Communication., 17, 1,. 61-91 (2007)

12. T. Nogami, F. Yoshida, Journal of Applied Social Psychology, The pursuit of self-interest and rule breaking in an anonymous situation., 43, 4,. 909916. Retrieved from: https://onlinelibrary.wiley.com/doi/full/10.1111/jasp. $\underline{12056}$ (2014)

13. O.S. Issers. LKI. Communicative strategies and tactics of Russian speech. M., (2008)

14. A. Mohammad, C. Vasquez. Journal of Sociolinguistics, 'Rachel's not here': Constructed dialogue in gossip, 19, 3,. 351-371. Retrieved from:https://onlinelibrary.wiley.com/doi/full/10.1111 /josl.12125 (2015)

15. Z. Vendler.. , Issues in the philosophy of language, Illocutionary suicide (1976) 